\title{
The patient's experience of primary ciliary dyskinesia: a systematic review
}

\author{
Laura Behan $^{1,2} \cdot$ Bruna Rubbo $^{1} \cdot$ Jane S. Lucas $^{1,3}$ - Audrey Dunn Galvin ${ }^{2}$
}

Accepted: 24 March 2017 / Published online: 30 March 2017

(C) The Author(s) 2017. This article is an open access publication

\begin{abstract}
Background Primary ciliary dyskinesia (PCD) is a rare genetic disorder characterised by progressive sinopulmonary disease, with symptoms starting soon after birth. The aim of this study is to critically review, analyse, and synthesise the literature in order to understand the experiences of patients with primary ciliary dyskinesia (PCD) and the impact on health-related quality of life.

Method MEDLINE, EBSCO, Cumulative Index to Nursing and Allied Health Literature (CINAHL), PsycINFO and EMBASE were searched according to the inclusion criteria. A qualitative analysis of 14 studies was conducted.

Results Fourteen studies were included in the review, five with qualitative methodologies. Studies originated from the UK, USA, Italy, Denmark and Belgium, one study included a survey distributed internationally. Significant relationships were found between age and worsening of respiratory symptoms, physical, and mental domains of health-related quality of life, with a greater decline compared with reference populations. Variations between the UK and Italy were found for health-related quality of life and its correlation with time since diagnosis. PCD was found to have a physical impact in all age groups: patients found it difficult to keep up with others, and found energy levels were easily
\end{abstract}

Laura Behan

1.behan@soton.ac.uk

1 Primary Ciliary Dyskinesia Centre, University Hospital Southampton NHS Foundation Trust, Southampton, UK

2 NIHR Southampton Respiratory Biomedical Research Unit, University of Southampton Faculty of Medicine and University Hospital Southampton NHS Foundation Trust, Southampton, UK

3 School of Applied Psychology, University College Cork, Cork, Ireland depleted compared to family or peers. In terms of social impact, symptoms lead to embarrassment and a sense of isolation, with patients concealing symptoms and/or their diagnosis. In turn, isolation was also linked with the lack of public and medical knowledge. In relation to emotional impact, anxiety was reported in a number of qualitative studies; patients were anxious about getting sick or when thinking about their future health. The burden of treatment and factors influencing adherence were also discussed in depth.

Conclusion Health-related quality of life decreases with age in patients with PCD. For all age groups, PCD was found to greatly impact physical, emotional, social functioning, and treatment burden. More research is needed on the psychosocial impact of the illness, disease burden and its effect on quality of life.

Keywords Primary ciliary dyskinesia $\cdot$ Patient perspective $\cdot$ Health-related quality of life $\cdot$ Patient experience

\section{Background}

Primary ciliary dyskinesia (PCD) is a rare, inherited lung disease affecting cilia motility such that mucociliary clearance is impaired. Individuals with PCD often present with unexplained neonatal symptoms such as neonatal cough, rhinitis transient tachypnoea, and pneumonia, often requiring respiratory support [1-3]. Patients continue to have persistent sinopulmonary symptoms in infancy. Chronic and progressive chest symptoms persist throughout life and include daily wet cough and recurrent chest infections which almost consistently lead to bronchiectasis $[4,5]$. By adulthood, bronchiectasis is present and some patients 
develop respiratory failure [2]. Upper airway symptoms include rhinosinusitis and recurrent serous otitis media with hearing impairment [6]. Situs inversus is found in approximately $50 \%$ of cases and situs ambiguous is seen in approximately $10 \%$ of cases $[6,7]$.

Assessment on the prevalence, burden of disease, and prognosis of PCD patients is difficult to determine due to a lack of representative international data. Reported prevalence varies from 1:2000 to 1:40,000; this could reflect true variability or could be a result of poor access to diagnostic facilities in some areas and countries [8-10]. A European Respiratory Society (ERS) Task Force survey of 26 European countries found that PCD is both under-diagnosed and diagnosed late [8].

As in most orphan diseases, research has focused on describing the pathophysiological mechanisms of the illness and improving diagnostics. Few studies have examined the psychosocial impact of the illness, disease burden, and its effect on health-related quality of life. This was highlighted by McManus back in 2003 [11], where a systematic search found no studies reporting from the patient perspective on impact to daily functioning, or on mental health and well-being.

The overall aim of this study was to synthesise the results from both qualitative and quantitative studies which examine the psychosocial impact of PCD. Through this synthesis, we evaluated qualitative studies documenting the experiences and views of PCD patients, the impact of the condition on their daily lives, in addition to health-related quality of life and any influencing factors. We included all age groups (adults, children, adolescents) and parents of PCD children. The qualitative studies allowed us to identify the most salient themes among age groups through interviews and focus groups analysis. The quantitative studies allowed us to compare patient-reported outcome measures (PROMs) and factors influencing variability. Finally, through this synthesis, we assessed the quality of the studies and made recommendations on future research needs.

\section{Method}

\section{Search strategy}

The systematic review was conducted using the Preferred Reporting Items for Systematic Review and Meta-Analyses Approach (PRISMA) [12]. The following electronic databases searched for papers published in the English language from inception until September 2015: MEDLINE-EBSCO, Cumulative Index to Nursing and Allied Health Literature (CINAHL), PsycINFO and EMBASE. Keywords and subject headings/MeSH terms searched in titles and abstracts using various combinations included: "ciliary dyskinesia, primary", "ciliary motility disorder", "Kartagener's syndrome", "primary ciliary dyskinesia", "perspective", "perception", "knowledge", "opinion", "psychological", "experience", "attitude", "impact", "view", "idea", "quality of life", "QOL", "HRQL", "patient report", "belief", and "awareness".

\section{Inclusion and exclusion criteria}

Inclusion criteria were primary studies that reported on experiences and perspective of PCD patients of all age groups or where patients completed PROMSs as primary or secondary outcomes. Quantitative, qualitative, and mixed methodologies were considered equally. PROMs were operationalised as generic health-related quality of life questionnaires, e.g. Short Form-36 (SF-36), and diseasespecific health-related quality of life questionnaires, e.g. St. George's Respiratory Questionnaire (SGRQ) and Leicester Cough Questionnaire (LCQ). Measures of psychological distress, e.g. Child Behaviour Checklist questionnaire and Parenting Stress Index-Short Form, were also included. Qualitative studies and mixed methods studies with a significant qualitative component were considered for inclusion if the number of participants was greater than one, and if sufficient methodological details and data were provided. Non-primary research articles (letters, commentaries, and reviews) were excluded.

\section{Search outcome}

The initial database search generated records from which articles were initially identified through screening of titles and abstracts as potentially relevant (LB and BR). Following removal of duplicates, papers of full text were read by two authors (LB and BR) to determine eligibility for inclusion. Discrepancies about whether a paper met the inclusion criteria were discussed with a third author (JSL) and a final decision was based on consensus. References of the full text articles assessed for eligibility were hand-checked to identify further papers that satisfied selection criteria.

\section{Data extraction and analysis}

The following data from included papers were extracted: author, date and location of study, aim, sample, design and methods, data collection and analysis, and results.

Data from included studies were systematically extracted using a standardised tabulated form (Table 4) by LB and BR independently, and then discussed and combined. In order to address the aims of this review, data were extracted on the results from health-related quality of life measures and patient-reported outcome measures. For qualitative studies, extracted data were compared across studies and 
grouped into themes to describe the issues pertinent to PCD patients.

\section{Quality appraisal}

Quality appraisals of data from both the qualitative and qualitative studies were independently assessed by LB and BR. The criteria for assessing the quality of quantitative studies as previously used by researchers [13-15] included study design, participants and recruitment, comparison group, number of participants, and quality of instrument used (Table 1). The total quality score ranged from 0 to 15 with each of the five criteria being score from 0 to 3. Quality assessment on the qualitative studies was performed using the Consolidated Criteria for Reporting Qualitative Health Research [16].

\section{Results}

\section{Study selection}

The initial database search generated 260 records from which 32 articles were initially identified through screening of titles and abstracts as potentially relevant (Fig. 1).
Removal of duplicates resulted in 26 papers of full text. Fourteen papers were identified for inclusion, two of which were conference abstracts where the full results were not available. For two additional abstracts (manuscripts now published) $[10,17]$, the authors had access to study results. No further papers were identified where references of the full text articles were hand-checked.

Studies included samples from the UK [11, 18-20], Italy [21-24], Denmark [25], and Belgium [26, 27] with collaborative works including participants from the UK and North America [17, 28] and an international study including participants from 25 countries [10]. Six studies consisted of cross-sectional surveys, two of which compared the PCD sample results with reference population norms [11, 20-22, 26, 27], one was a longitudinal survey given at two time points [23], three were case-control design including healthy samples for comparison [24, 25]. Four used a qualitative approach [17-19, 28] and one used a mixed method approach [10]. Three of the UK studies [11, 19, 20] were carried out using the same study population. The two Belgian studies were also conducted on a shared sample. Sample sizes ranged from 5 to 270 . Apart from one study, gender was reported and all contained both male and female samples (Table 2).

Table 1 Criteria for rating methodological quality of quantitative studies

\begin{tabular}{|c|c|c|}
\hline Study parameter & Rating & Criteria \\
\hline \multirow[t]{4}{*}{ Study design } & 3 & Longitudinal prospective design (explicitly stated) \\
\hline & 2 & Retrospective or mixed design (explicitly stated) \\
\hline & 1 & Cross-sectional (explicitly stated) \\
\hline & 0 & Survey or did not report \\
\hline \multirow[t]{4}{*}{ Participants and recruitment } & 3 & $\begin{array}{l}\text { (1) Description of the population, (2) eligibility of participants, (3) precise details of the recruitment } \\
\text { process, (4) accounted for the number recruited, (5) loss to follow up }\end{array}$ \\
\hline & 2 & Minimal description of at least four criteria \\
\hline & 1 & Two criteria missing \\
\hline & 0 & More than two criteria missing \\
\hline \multirow[t]{4}{*}{ Comparison group } & 3 & Healthy, age-appropriate comparison (i.e. adolescents/young people aged 13-25 years) \\
\hline & 2 & Reference sample \\
\hline & 1 & Other comparison group (i.e. adults) \\
\hline & 0 & No comparison group \\
\hline \multirow[t]{4}{*}{ Number of participants } & 3 & $n>100$ \\
\hline & 2 & $n=50-100$ \\
\hline & 1 & $n<50$ \\
\hline & 0 & Did not report \\
\hline \multirow[t]{4}{*}{ Instruments used } & 3 & Psychometrically sound report of instruments used \\
\hline & 2 & Some weak psychometric properties reported \\
\hline & 1 & $\begin{array}{l}\text { Psychometric properties of instruments reported as inadequate for measuring HRQoL or IQ, physical } \\
\text { functioning. etc }\end{array}$ \\
\hline & 0 & No psychometric properties reported \\
\hline
\end{tabular}

Adapted from previously reported studies [13-15] 
Fig. 1 PRISMA Flow Diagram for search to investigate PCD from the patients' perspective
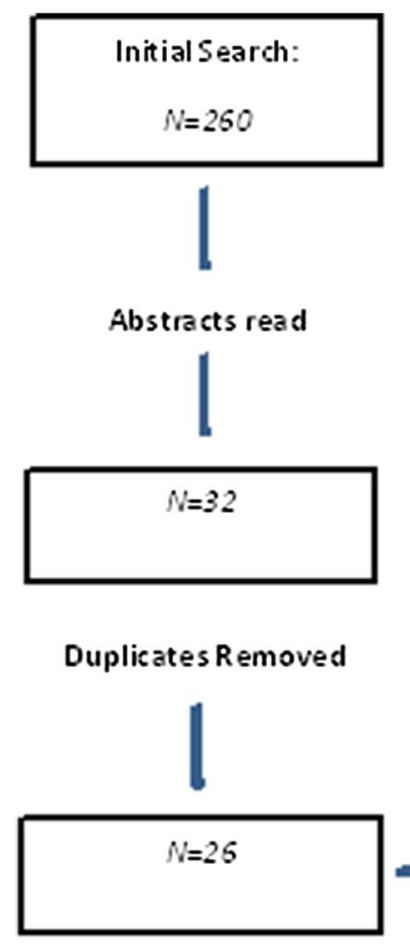

Full Text Reads

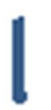

Studies for Inclusion:

$N=14$
12 studies were excluded:

- 2 studies were comment aries

- 1 study was a case report

- 9 were irrelevant as they did not report findings from patient reported outcome measures, quality of life or qualitative data on patient experience

\section{Methodological quality}

Quality appraisal of the quantitative studies points to deficits, in particular to study design, and recruitment and inclusion of a comparison group (Table 3). Psychometric properties of the measures were cited in five of the quantitative studies; however, the internal reliability of the measures, i.e. Cronbach's alpha within the sample population, was not reported in any of the studies. The application of the measures was not clear for all studies. For some studies, measures used were not developed/adapted and validated specifically for younger children. Most studies were surveys (with one being longitudinal) and although it was apparent that these studies were cross-sectional, this was not stated explicitly in all. The study which ranked the highest had a score of 8 out of 15 points; this was a cross-sectional survey study where 78 patients completed a questionnaire which collected information on age of diagnosis, symptoms and likely PCD-specific problems in addition to disease-specific and general HRQoL (using the St. George's Respiratory Questionnaire and the Medical Outcomes Study Short
Form-36 (SF-36)). Use of the SF-36 allowed for scores to be compared with the healthy Italian population.

For the four qualitative studies, criteria of the COREQ32 item checklist are generally adhered to Table 4 . The main deficits in reporting were the characteristics of the research team and the relationship between interviewee and interviewer, description of the coding tree, and the provision of feedback to the interviewee.

\section{Methodologies of quantitative and qualitative studies}

Six studies assessed health-related quality of life (HRQoL) in PCD patients. HRQoL measures are generic or diseasespecific. Disease-specific measures assess special states and concerns of different diagnostic groups and are important for the detection of small clinically important changes. The most commonly used disease-specific HRQoL measure in this review was the St. George's Respiratory Questionnaire (SGRQ) for chronic obstructive pulmonary disease $(n=6)$. Other disease-specific outcome measures used included the HRQoL measure for cystic fibrosis (CFQ-R) $(n=1)$, a 


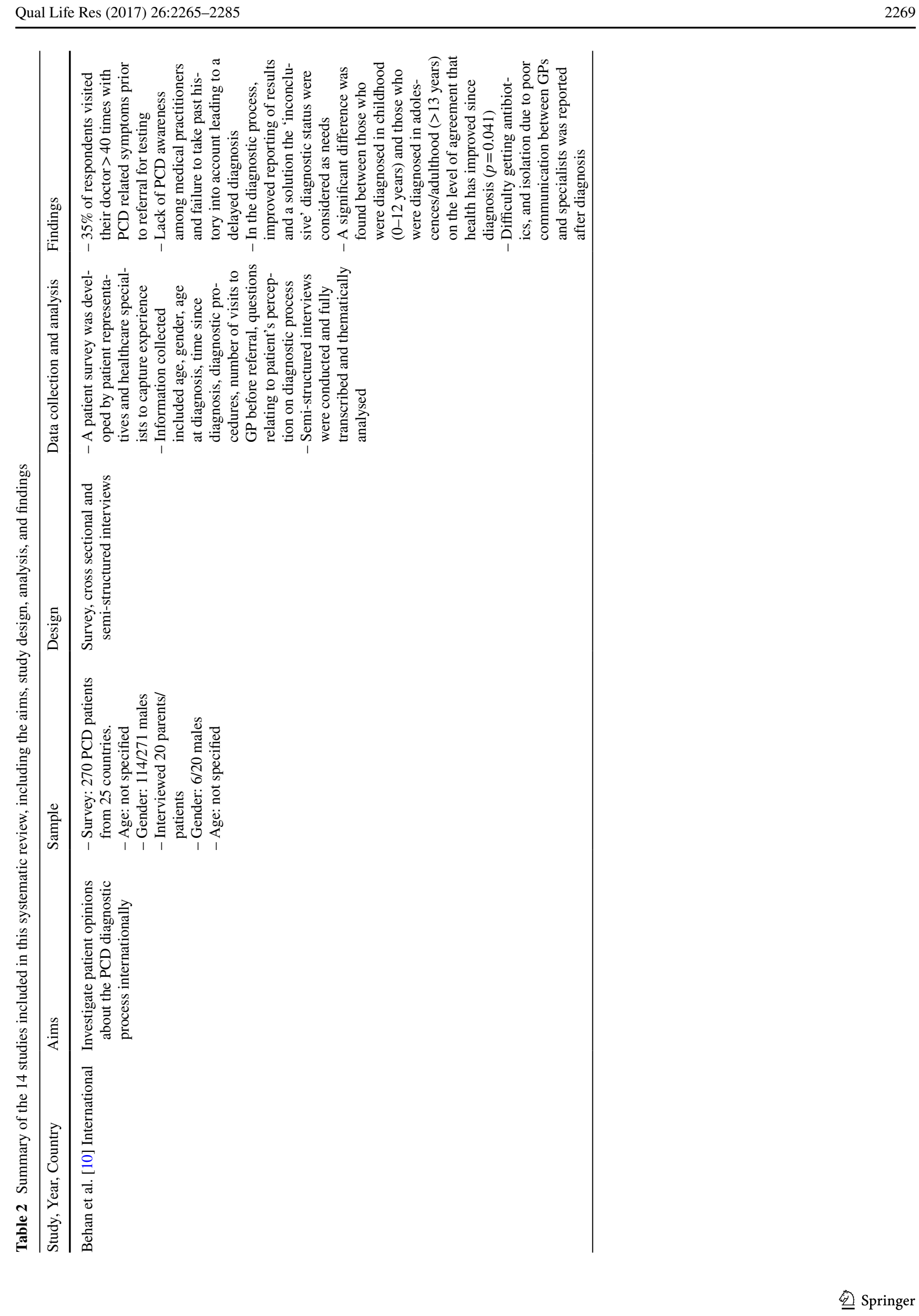




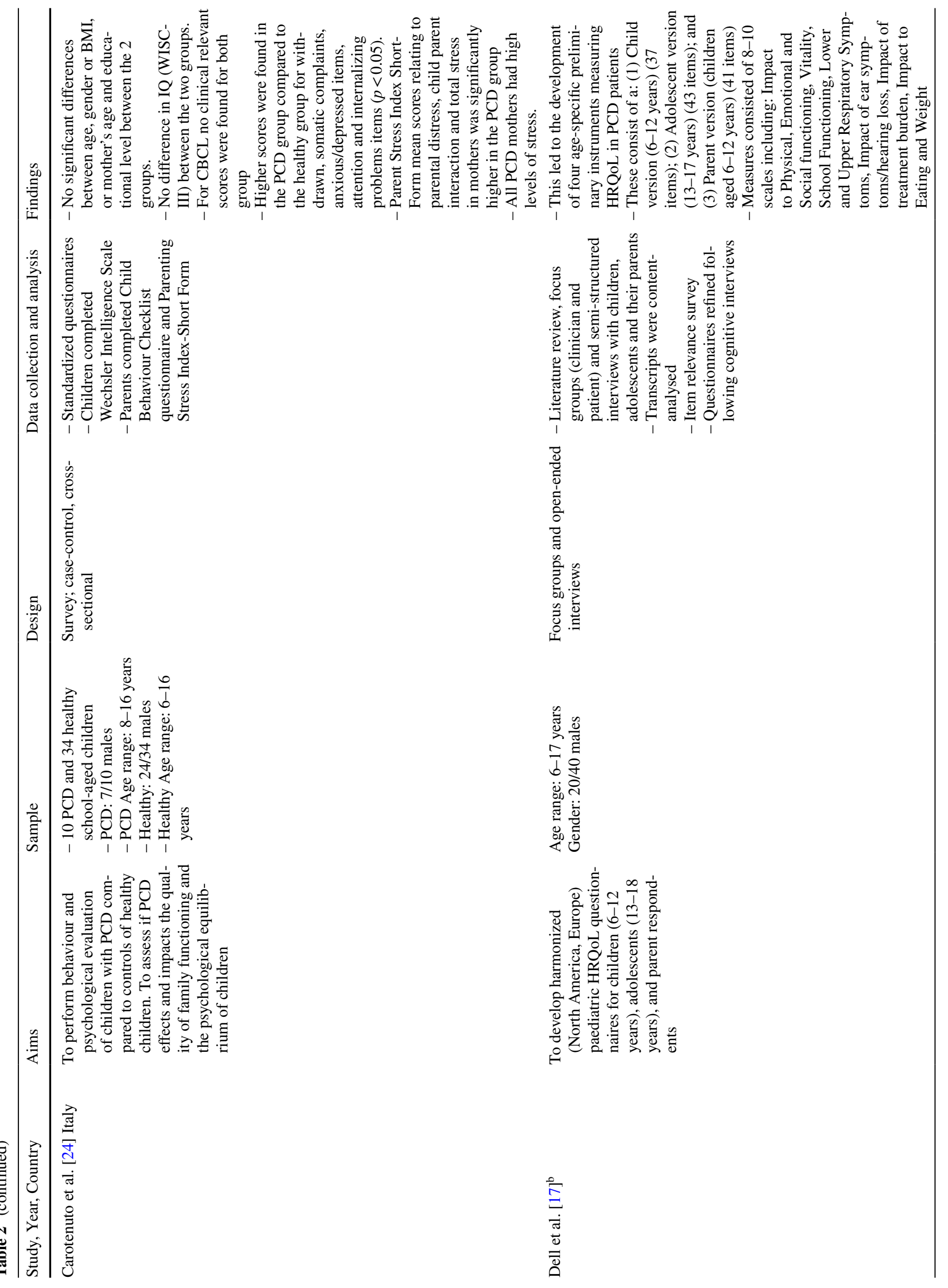




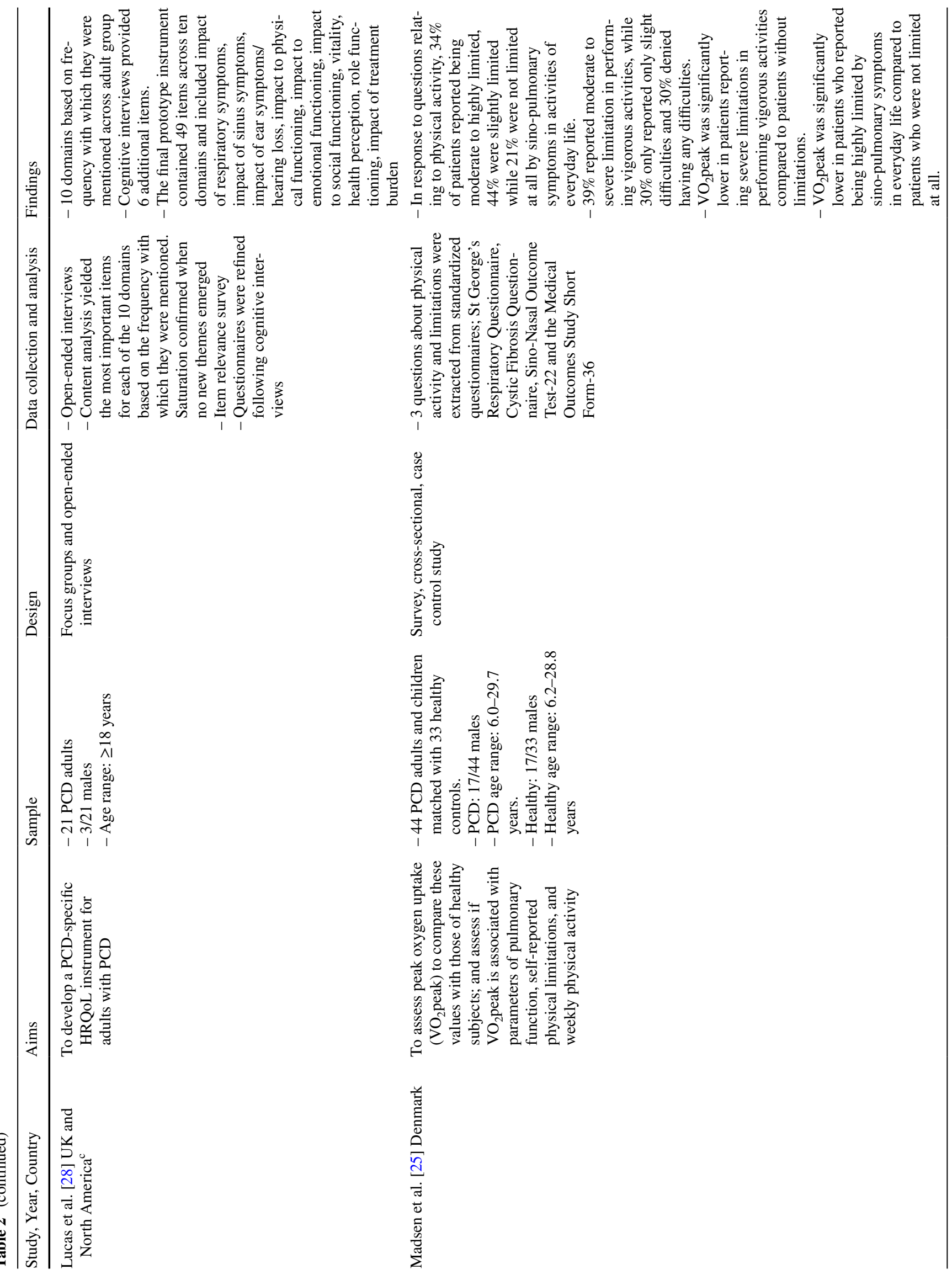




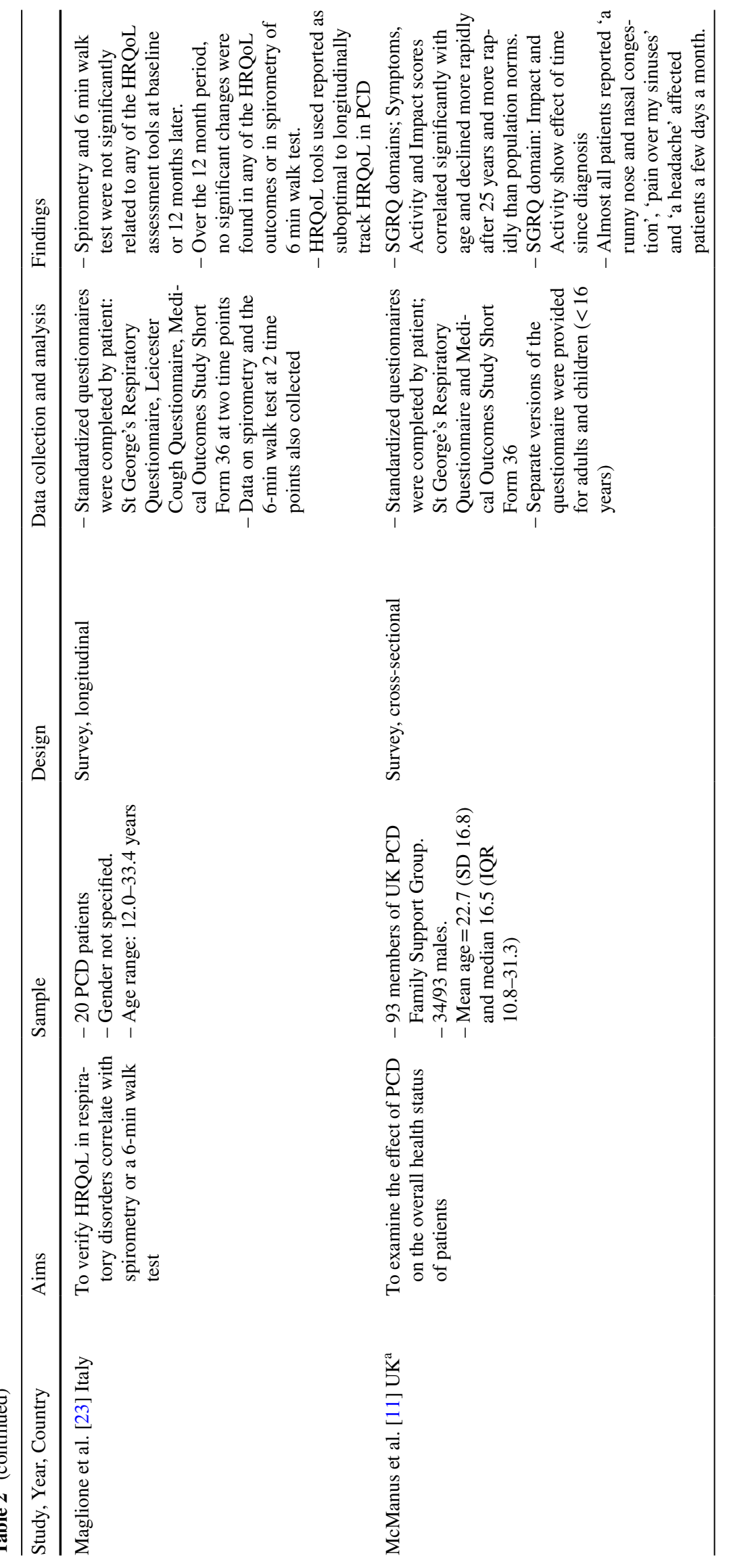




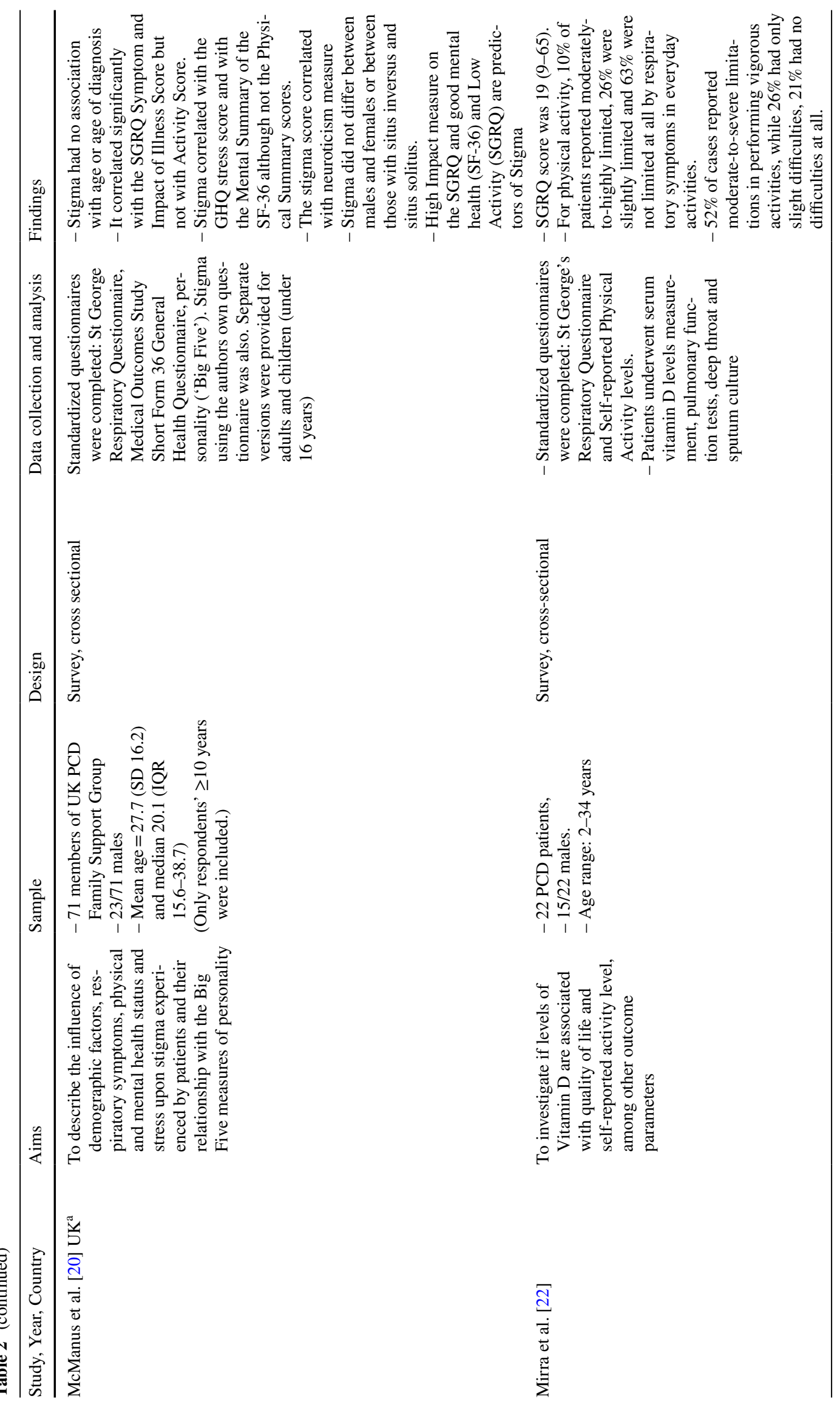




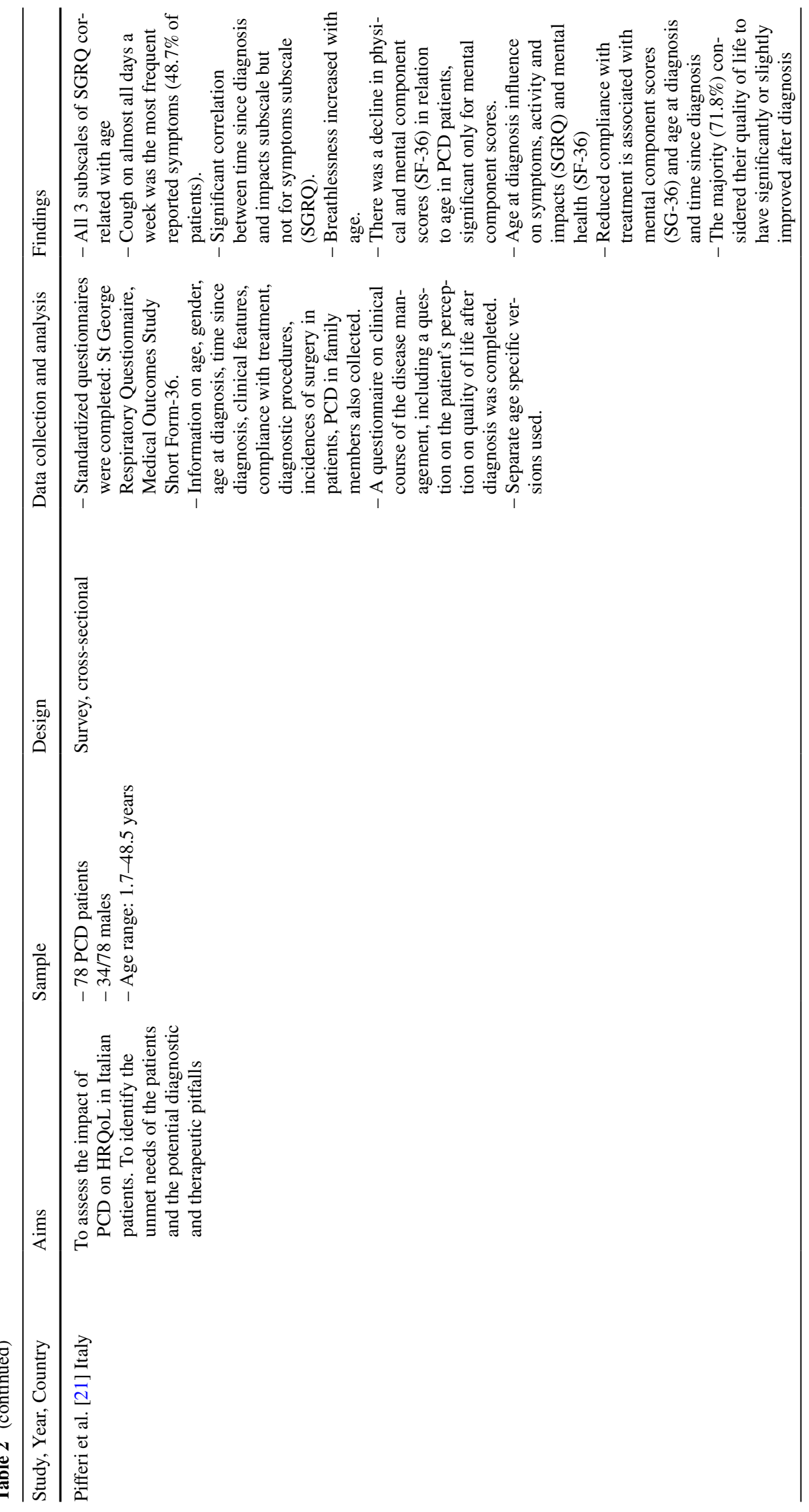




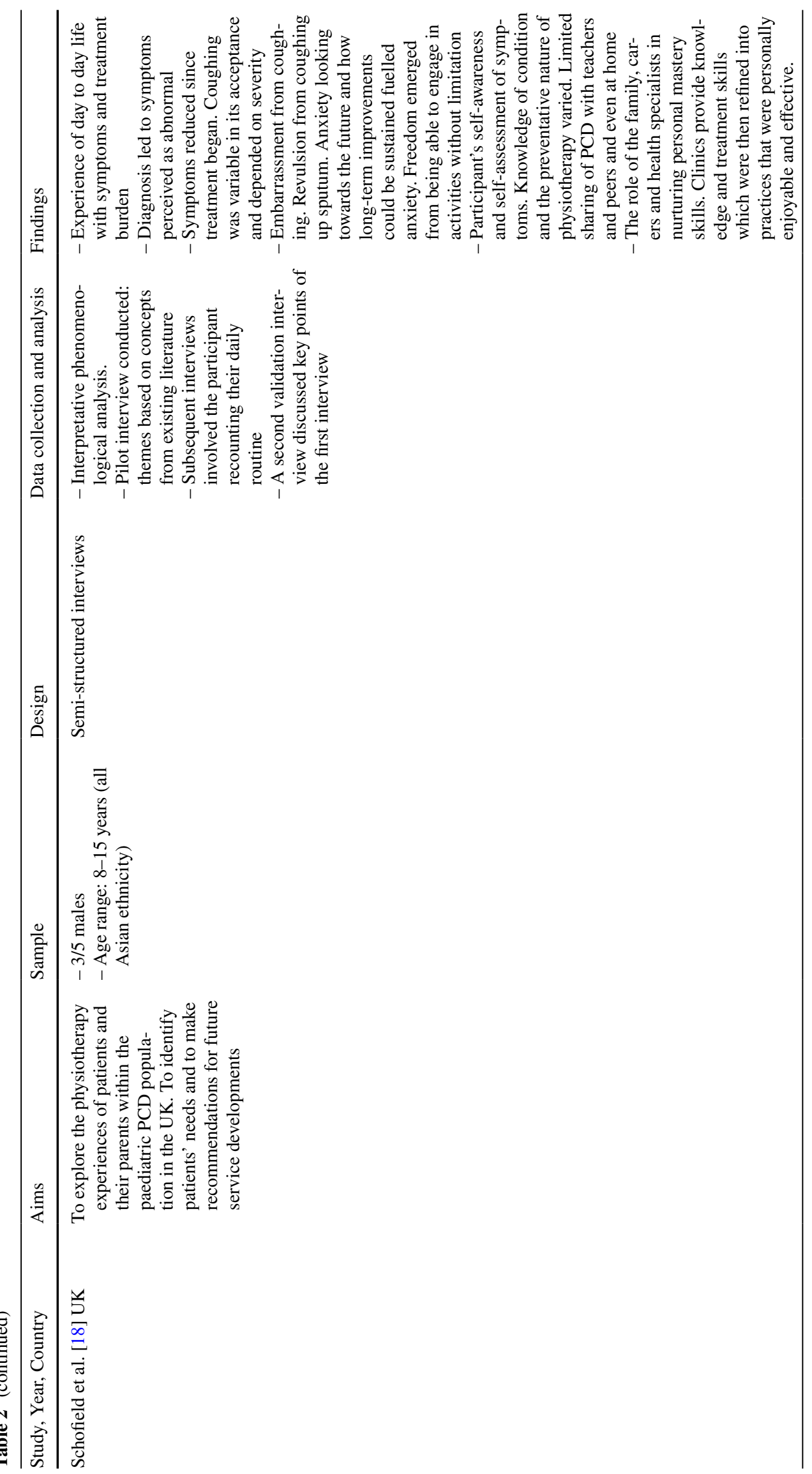




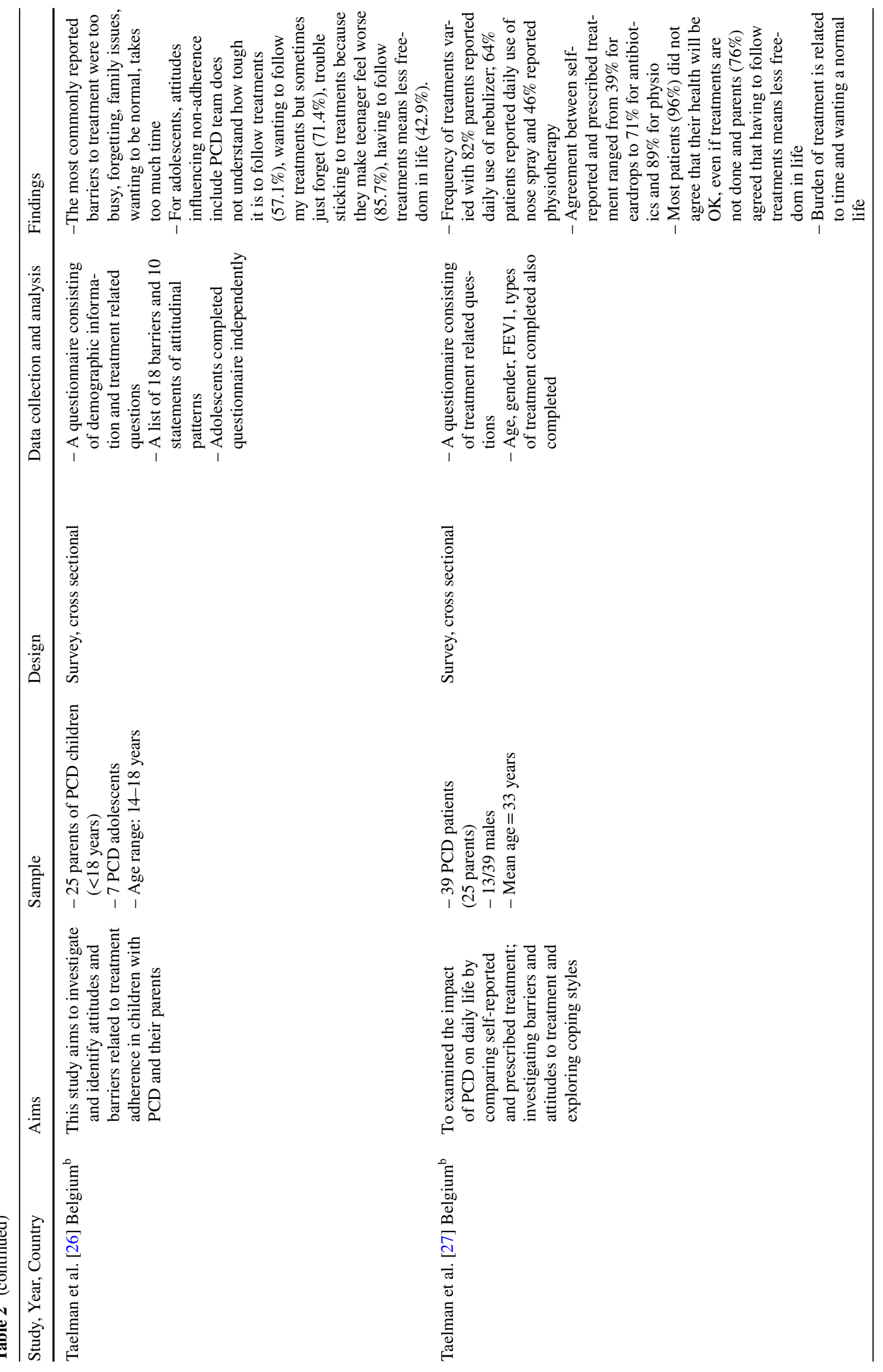




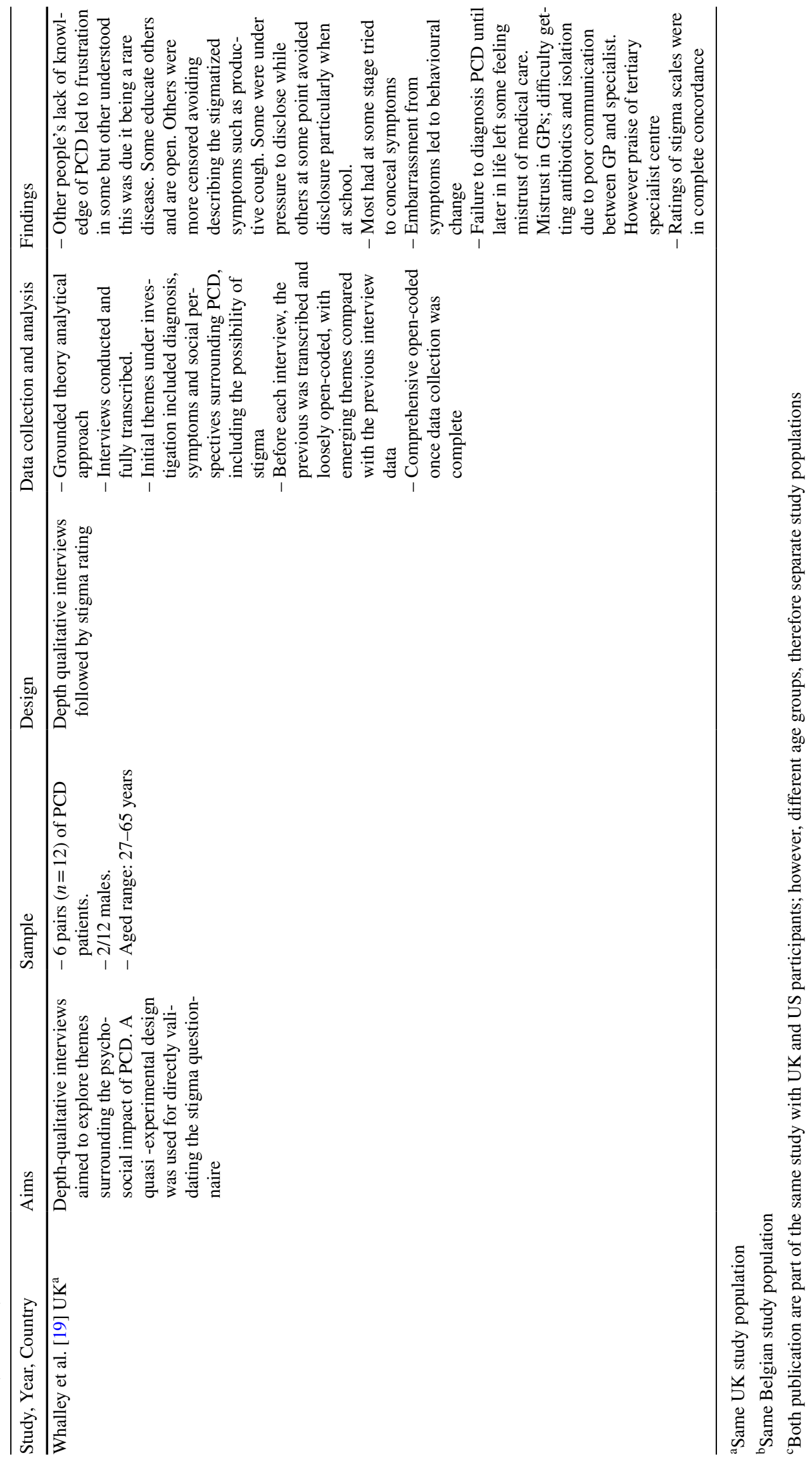


Table 3 Summary of the quality of the data and studies contributing to the quantitative studies included in this systematic review

\begin{tabular}{lllllll}
\hline & Study design & $\begin{array}{l}\text { Participants } \\
\text { and recruit- } \\
\text { ment }\end{array}$ & $\begin{array}{l}\text { Com- } \\
\text { parison } \\
\text { group }\end{array}$ & $\begin{array}{l}\text { Number of } \\
\text { participants }\end{array}$ & Instruments & Total \\
\hline Behan et al. [10], International & 0 & 2 & 0 & 3 & 0 & 5 \\
Carotenuto et al. [24], Italy & 0 & 0 & 3 & 1 & 2 & 6 \\
Madsen et al. [25], Denmark & 1 & 2 & 3 & 1 & 0 & 7 \\
Maglione et al. [23], Italy & 3 & 0 & 0 & 1 & 0 & 4 \\
McManus et al. [20], UK & 0 & 1 & 0 & 2 & 2 & 5 \\
McManus et al. [11], UK & 0 & 1 & 2 & 2 & 2 & 7 \\
Mirra et al. [22] & 1 & 0 & 0 & 1 & 2 & 4 \\
Pifferi et al. [21], Italy & 1 & 1 & 2 & 2 & 2 & 8 \\
Taelman et al. [27], Belgium & 0 & 0 & 0 & 1 & 0 & 1 \\
Taelman et al. [26], Belgium $^{\mathrm{b}}$ & 0 & 1 & 0 & 1 & 0 & 2 \\
\hline
\end{tabular}

Scoring was according to Criteria for Rating Methodological Quality of Quantitative Studies adapted from previous studies [13-15]

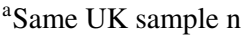

${ }^{\mathrm{b}}$ Same Belgian sample
HRQoL measure for sinonasal conditions: The Sino-Nasal Outcome Test (SNOT-22) $(n=1)$, and the Leicester Cough Questionnaire (LCQ) $(n=1)$. To assess the impact of PCD on HRQoL, related to mental health and well-being, the Medical Outcomes Study Short Form 36 (SF-36) was used in five of the studies. Other patient-reported measures that measured outcomes other than HRQoL included the Wechsler Intelligence Scale for Children, the Child Behaviour Checklist questionnaire, the Parenting Stress Index-Short Form and the Self-reported Physical Activity Measure. One study included a questionnaire measuring Stigma [20]. This was developed by the author and stigma was assessed by the patient's response to 11 items on embarrassment about symptoms, feeling a nuisance to friends or family, concealment of condition, etc. Four of the studies were cross-sectional, single-occasion, singlecentred studies. One study was a cross-sectional, singleoccasion, single-centred case-control study, and one was a cross-sectional, longitudinal, single-centred study with measures repeated after 1 year.

\section{Main themes}

\section{Factors influencing health-related quality of life}

In a cross-sectional UK survey [11], a slight decline in HRQoL was found for all three domains of the SGRQ (Activity, Impacts and Symptoms) until the age of 25 years after which a more rapid decline occurred. The physical component score of the SF-36 also showed a continual decline with age so that by the age of 40 onwards, the health status of PCD patients was one and a half standard deviations below the population mean. In contrast, the mental component score also declined with age however the declining health status broadly parallels that found in the general population as a whole, and was, at the most, onethird to one-half a standard deviation below the population norms. Age was also an important factor in an Italian crosssectional survey study [21], where all three subscales of the SGRQ and the physical and mental component scores of the SF-36 declined significantly greater than norms for the corresponding Italian population. These declines, however, were found to be earlier in age than those reported in the UK study [11], where deterioration mainly occurred prior to and during adolescence. In the UK study, little abnormality was found for the childhood and adolescence study population when compared to standard measures of the SF-36.

Both studies found that patients with an earlier diagnosis had better scores for the SGRQ Impact and Activity subscales, suggesting the importance of early medical intervention for HRQoL. The Italian group found a clear majority of patients $(71.8 \%)$ considering their quality of life significantly or slightly improved after diagnosis; however, there remained a progressive worsening of the disease over time. This was in contrast to the UK group who reported stable scores for patients after diagnosis.

\section{Physical impact}

Ten studies addressed the impact of PCD on physical functioning $[10,11,17,18,20-23,25,28]$. The physical impact of PCD was reported by children, teenagers, and their parents in a qualitative study using phenomenological analysis methods [18]. Coughing was regularly mentioned by all participants in their accounts of daily activities, as was the impact of their cough on activities when both well and unwell. Symptomatic relief of chest symptoms was reported 
Table 4 Summary of completeness of reporting for the qualitative studies included in this systematic review using the Consolidated Criteria for Reporting Qualitative Health Research [16]

\begin{tabular}{|c|c|c|}
\hline Reporting criteria & No $(\%) n=5$ & $\begin{array}{l}\text { References of stud- } \\
\text { ies reporting each } \\
\text { criterion }\end{array}$ \\
\hline \multicolumn{3}{|l|}{ Characteristic of research team } \\
\hline Interviewer/facilitator identified & $4(80 \%)$ & {$[23,24,35,36]$} \\
\hline Credentials & $2(40 \%)$ & {$[23,35]$} \\
\hline Occupation & $2(40 \%)$ & {$[23,35]$} \\
\hline Gender & $0(0 \%)$ & - \\
\hline Experience and training & $2(40 \%)$ & {$[23,35]$} \\
\hline \multicolumn{3}{|l|}{ Relationship with participants } \\
\hline Participation knowledge of the interviewer & $2(40 \%)$ & {$[23,35]$} \\
\hline Interviewer characteristics & $3(60 \%)$ & {$[23,24,35]$} \\
\hline Methodological orientation and theory & $5(100 \%)$ & {$[23,24,34-36]$} \\
\hline \multicolumn{3}{|l|}{ Participant selection } \\
\hline Sampling method (for example, snowball or purposive) & $5(100 \%)$ & {$[23,24,34-36]$} \\
\hline Method of approach & $5(100 \%)$ & {$[23,24,34-36]$} \\
\hline Sample size & $5(100 \%)$ & {$[23,24,34-36]$} \\
\hline Non-participation & $2(40 \%)$ & {$[23,24]$} \\
\hline \multicolumn{3}{|l|}{ Setting } \\
\hline Setting of data collection & $4(80 \%)$ & {$[23,34-36]$} \\
\hline Presence of non-participants & $1(20 \%)$ & [23] \\
\hline Description of sample & $5(100 \%)$ & {$[23,24,34-36]$} \\
\hline \multicolumn{3}{|l|}{ Data collection } \\
\hline Interview guide & $5(100 \%)$ & {$[23,24,34-36]$} \\
\hline Repeat interviews & $1(20 \%)$ & [23] \\
\hline Audio/visual recording & $5(100 \%)$ & {$[23,24,34-36]$} \\
\hline Field notes & $3(60 \%)$ & {$[23,24,36]$} \\
\hline Duration & $2(40 \%)$ & {$[23,24]$} \\
\hline Data saturation & $4(80 \%)$ & {$[23,34-36]$} \\
\hline Transcripts returned to participant & $0(0 \%)$ & - \\
\hline \multicolumn{3}{|l|}{ Data analysis } \\
\hline Number of data coders & $5(100 \%)$ & {$[23,24,34-36]$} \\
\hline Description of the coding tree & $0(0 \%)$ & - \\
\hline Derivation of themes & $5(100 \%)$ & {$[23,24,34-36]$} \\
\hline Protocol for data preparation and transcription & $5(100 \%)$ & {$[23,24,34-36]$} \\
\hline Software & $4(80 \%)$ & {$[23,34-36]$} \\
\hline Participants' feedback or member checking & $3(60 \%)$ & {$[23,34,35]$} \\
\hline \multicolumn{3}{|l|}{ Reporting } \\
\hline Participant quotations presented & $5(100 \%)$ & {$[23,24,34-36]$} \\
\hline Data and findings consistent & $5(100 \%)$ & {$[23,24,34-36]$} \\
\hline Clarity of major themes & $5(100 \%)$ & {$[23,24,34-36]$} \\
\hline Clarity of minor themes & $5(100 \%)$ & {$[23,24,34-36]$} \\
\hline
\end{tabular}

as leading to a sense of freedom at being able to undertake activities without restrictions. Patients reported feeling limited in their ability to keep up with peers because of coughing, breathlessness, fatigue and low energy levels. Similar themes arose in two collaborative qualitative studies, which included interviews with patients from the UK and North America [17, 28]. Children and teenagers reported they became tired quickly when engaging in physical exercise and needed to request more breaks than their peers. This theme relating to the physical impact of PCD was also found in adult interviewees, where patients reported not being able to keep up with others when walking or exercising (Box 1).

In a quantitative study, $10 \%$ of patients were found to be moderately-to-highly limited by respiratory symptoms in everyday activities, and $52 \%$ of cases had moderate-tosevere limitations in performing vigorous activities [22]. This was in contrast to a Dutch study where $34 \%$ of patients 
Box 1 Patient experiences of the physical impact of PCD

A: "I go running again and then cough a bit and then I'll stop" Child [18]

B: "I had to tell the group not to worry because I start huffing and spluttering as I'm walking." Adult [28]

"My air goes out because I'm running and I can't speak and then I'm not speaking and sometimes my air goes down a bit and then I can't, and then I just can't, I can't, I can't take it." Child [18]

“...if he's playing in school and ...he needs to run around, then he gets more tired than other kids and they're still running around and he's stopping." Parent [17]

reported being moderately-to-highly limited by sinopulmonary symptoms in activities of everyday life, and 39\% reported moderate-to-severe limitations in performing vigorous activities. None of the healthy controls reported any limitations in physical abilities.

As reported previously, a continual decline according to age in scores on the physical domain of the SF-36 reflected a moderate degree of morbidity on normal physical functioning which is progressive across the lifespan [11]. Cough, on almost all days of the week in the last 12 months, was the most frequently reported symptom ( $48.7 \%$ of patients) regardless of age, together with excessive sputum $(57.7 \%$ of patients) [21].

\section{Emotional impact: frustration, anxiety and stress}

The emotional impact was explored in depth in three of the five the qualitative studies [17, 18, 28]. Interviews in the UK and North America explored the emotional impact of PCD in all age groups [17, 28]. In the paediatric group, frustration relating to treatment burden was a prominent theme. Children and adolescents reported feeling frustrated about getting sick regularly and about the chronic nature of their symptoms. In addition, a sense of unfairness and sadness about having this condition was reported. A UK qualitative study [18] found that children and teenagers became anxious when thinking about their health in the future. The positive changes which had arisen from their diagnosis and effective health care, while appreciated, induced a level of doubt and anxiety as to how these improvements could be sustained. Such feelings of anxiety were also found in a series of interviews with adult patients [28]. This was especially the case when thinking about their future and future health. They reported feeling anxious about being able to conceive children as well as being well enough to care for their family (Box 2).

Carotenuto et al. conducted a behavioural and psychological evaluation of children with PCD and compared the results to healthy children [24]. The findings showed no clinically relevant scores for both healthy and PCD groups. However, higher scores were found in the PCD group for factors such as withdrawnness, somatic complaints, anxious/depressed items, attention span, and internalising problems items $(p<0.05)$. This study also found that total stress levels [assessed through the parenting stress index-short form (PSI/SF)] in mothers were significantly higher in the PCD group than in mothers of healthy controls $(p<0.01)$, and that all PCD mothers had high levels of stress.

\section{Social impact: Stigma, embarrassment and concealment}

In the qualitative studies, symptoms such as coughing, sputum production, and ear drainage were reported as causing embarrassment among paediatric patients [17, 18, 28]. Acceptance of coughing was found to be variable among participants and depended on severity. There was also a sense of revulsion from coughing up sputum. Symptom relief led to patients feeling 'normal' [18] (Box 3), paradoxically a reluctance to adhere to treatments was also attributed to wanting to feel normal [26, 27]. Adult patients also reported embarrassment [19], with patients concealing symptoms such as coughing and blowing their nose. In a study assessing stigma (measured using a questionnaire developed for this study) [20], 75\% of the sample agreed that their coughing or breathing was embarrassing

Box 2 Patient experiences of the emotional impact of PCD

A: "I was sick on and off...it's just frustration. Because there's no cure." Adolescent [17]

B: "Sometimes, when he sees his friends running around and he can't tag them, then he feels like why do I have PCD?" Parent [17]

C: "It...just wastes all of my energy, it makes me feel like I don't want to wake up in the mornings" Child [17]

D: "I'm so frustrated with this illness, I just want it to go away, but, unfortunately, that's how I have to live." Adult [28]

E: “...if you go to the doctor [and] you're feeling pretty good and you know your numbers are not good; that can be a big cause of anxiety." Adult [28]

F: "Finding out that I possibly can't have kids; that are when it started to panic me a little bit." Adult [28]

G: "I'm still very uncertain if I ever wanna have children because I don't know how me having this illness will affect them.” Adult [28] 
Box 3 Patient experiences of the emotional impact of PCD

A: “actually coughing up mucus isn't a very nice thing. It's not, it's quite a sort of...frowned on in society kind of thing isn't it so I kind of, yeah, I don't think it's very nice, sort of, to do it in front of people" Adult [19]

B: 'Sometimes I raise my hand and then say, 'I have to blow my nose.' And then I go in the bathroom....and shut the door because I don't want anyone to hear me [because] it's embarrassing." Child [17]

C: "I feel like I'm being judged by other people because I constantly sniff and...cough.” Teenager (Dell)

D: "If she has a speech problem or...coughing constantly...when they're in school, it might become embarrassing." Parent [17]

E: When I cough. .. it feel a bit more, erm.. . like I've got PCD, but when I don't cough I just feel normal. Child [18]

in public. It also found that stigma correlated with symptoms and impact of illness from the SGRQ but not with activities. It also correlated with the mental health component scores of the SF-36 but not for the physical component scores.

Paediatric patients were found to be reluctant to share their PCD diagnosis with teachers and peers or even to talk about their condition at home [18]. In a separate UK study of patient $\geq 10$ years, $45 \%$ of patients agreed in a study-specific questionnaire that they have sometimes felt they had to hide their condition from other people [20]. Following on from this, a qualitative study [19] found that some patients felt frustrated by lack of knowledge of PCD in the general public. While some interviewees were keen to educate others and were open to discuss their illness, others were more censored, and avoided describing their symptoms. The likelihood of disclosure may be dependent on context, since some patients felt under pressure to disclose their diagnosis, for example, to teachers or work managers on an account of needing time off when ill. There were other patients who reported avoiding open disclosure, particularly when at school (Box 3).

\section{Lack of PCD awareness among medical practitioners}

A mixed method study [10] reported the accounts of 20 adult patients and parents of children and teenagers from nine different countries on their experience of being diagnosed with PCD or going through the diagnostic process. The most prominent theme reported among interviewees was a frustration with the lack of PCD awareness among medical practitioners, manifesting initially in the failure of general practitioners (GPs) to refer them for PCD diagnostic testing. This was also found in a UK-based qualitative study, using grounded theory analytical methods [19] where failure to diagnosis PCD until later in life left some patients feeling distrustful of medical care. Themes such as distrust in GPs, difficulty getting antibiotics, and isolation due to poor communication between GPs and specialists were reported by both studies [10, 19].

\section{Treatment adherence and treatment burden}

Two abstracts $[26,27]$ from a survey using the same sample but presenting separate results examined treatment adherence. A range in the levels of agreement was found between self-reported and prescribed treatment, ranging from $39 \%$ for eardrops, to $71 \%$ for antibiotics, and $89 \%$ for physiotherapy. Barriers to completing treatments included being too busy, forgetting about treatments, family issues, and treatments taking too much time. For adolescents, 57\% agreed that their PCD team do not understand how difficult it is to follow treatments, and $43 \%$ felt that having to follow the PCD treatments meant less freedom in life. The difficulty of fitting treatments in on a daily basis was reported by 12/20 adolescents interviewed across the UK and North America [17]. Interviews with adult PCD patients also reported the challenges of completing their treatments $[10$, 28] (Box 4).

There was agreement among parents of children with PCD (76\%) that barriers to completing treatments meant less freedom in life [26]. Parents expressed how other commitments, such as siblings and employment, could limit their ability to complete daily treatments $[17,18]$ (Box 4).

Box 4 Patient's experiences of treatment burden

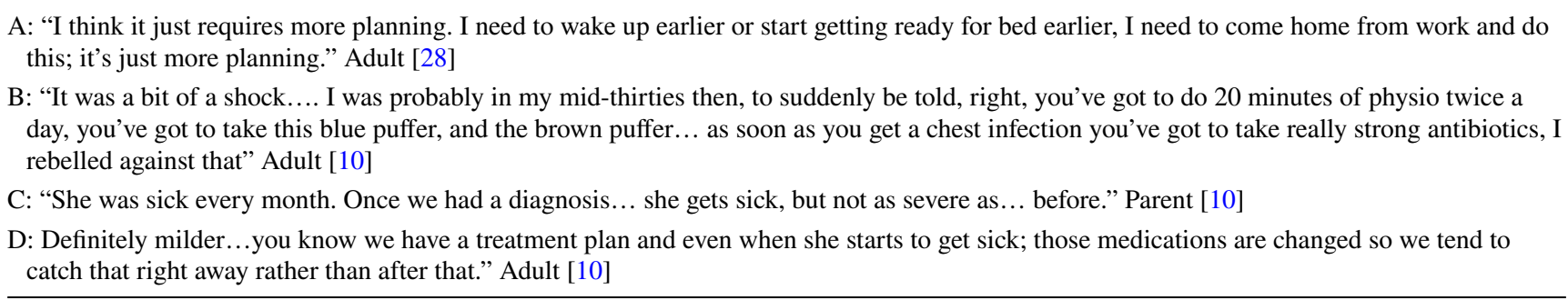


Patients did report that following a PCD diagnosis, treatments could reduce symptoms providing sensations of relief. There was a subjective perception of physiotherapy treatments, corresponding to fluctuating levels of motivation. There was also a variance different levels of PCD health literacy knowledge in the preventative nature of physiotherapy among children and teenagers [18]. In a cross-sectional survey study [26], 86\% agreed that they had difficulty complying with treatments because they made them feel physically worse; however, $96 \%$ of patients acknowledged their health would decline without treatments. In the mixed methods study by Behan et al., a study-specific survey [10] found a significantly higher level of agreement that health had improved since diagnosis $(p=0.041)$ in those diagnosed in childhood (0-12 years) compared to those who were diagnosed in adolescences/ adulthood ( $>13$ years).

\section{Discussion}

This systematic review identified 14 studies focussing on the perspectives, opinions, and attitudes of patient with PCD. Most of the quantitative studies consisted of small cross-section surveys and the methodological quality of these studies was generally low (Table 3). While the qualitative studies provided a deeper insight into the patient experience, only a small number of these studies exist, and mostly include patients from the UK and North America. Notwithstanding these weaknesses, the evidence assembled from the studies makes an important contribution to understanding the PCD patient experience and associated influences relating to quality of life.

Two cross-sectional studies suggested a correlation between age and worsening of respiratory symptoms, general physical and mental quality of life. Within these two studies, variances exist with Pifferi reporting an early decline in HRQoL and McManus reporting little abnormality in standard measures of SF-36 during childhood and adolescence. Also the variances between the two studies could be due to differences in the age of participants involved or a result of their limited sample size. It could also be due to cultural differences between the countries (UK and Italy), access to specialist diagnostic, and management services or treatment adherence may also account for differences. Caution must be exercised in the interpretation of these findings. Cross-sectional studies do not take into account confounding factors such as differences between adult and child participants and experience which may affect changes over time, i.e. diet, tobacco smoke exposure, etc. The progressive nature of PCD and the deterioration of health have been described in other studies through physiological methods such as spirometry [5]. Werner et al. [29] have shown the percentage-predicted forced expiratory volume in $1 \mathrm{~s}$ (FEV1\% pred) values versus age exhibited a mean annual decline of $0.59 \%$. The results show interesting trends and however highlight the need for large longitudinal international studies before more reliable conclusions can be made. The Genetic Disorders of Mucociliary Clearance Consortium (GDMCC), the iPCD cohort and the BESTCILIA registry are examples of ongoing large-scale studies that will contribute to this aim.

The physical impact of PCD was a prominent theme in both the qualitative and quantitative studies. This was defined by the most prominent feature of this illness: coughing. Coughing was regularly mentioned by interviewees of all age groups [17, 18, 28]. It was the most frequently reported symptom in a survey of 78 participants, where $48.7 \%$ reported having to cough nearly all days of the week for the past 12 months [21]. Persistent presence of cough was found to be far less prevalent than that in other studies [10,30] where it was found to be as high as 93-100\%. This could be as a result of the way in which the question was phrased or the method of data collection used, i.e. patient reporting at home or reporting to a clinician in a hospital setting. Severity of symptoms might also reflect different data collection points, with patients on their first referral appointment prior to diagnosis and commencement of treatments exhibiting more severe symptoms. The physical impact of PCD was expressed by patients in the qualitative studies, as not being able to keep up with other family members and peers due to fatigue [17, 18, 28].

Questionnaire findings [24] showed that PCD children were more likely to be withdrawn, experience anxiety or depression, and internalise more problems than the healthy population. PCD was found to affect the parent also with significantly higher stress being reported in mothers of children with PCD. No other PCD study reports on these factors; however, studies in children and parents with cystic fibrosis have also reported elevated levels of depression, stress and anxiety compared to healthy populations $[31,32]$. The synthesis of the qualitative studies allows the researcher to conclude possible reasons for this. PCD impacts greatly on the emotional functioning of patients in all age groups. Children described the frustration of having constant symptoms and recurrently getting sick. Patient anxiety was expressed, especially when thinking about the near and distant future. Children reported feeling worried about their health and of getting sick. A sense of sadness was reported because of their awareness of being different from other children. There is a need for further exploration on how PCD causes stress in developmental ages and the psychological effects of PCD on intra-familiar relationships.

Concealing PCD symptoms such as cough and blowing nose in public were reported across the qualitative studies 
[17-19, 28]. Embarrassment was mostly from coughing and producing sputum in public; however, ear drainage was also reported as an embarrassing symptom in one of the paediatric studies [17]. The stigma questionnaire (which included items on embarrassment from symptoms and concealment) correlated with mental health and the social impact of symptoms. Although the impact of PCD on school functioning was expressed by patients $[17,28]$, no differences in educational level or IQ were found between PCD children and healthy children. School functioning instead could be related to patients' reluctance to disclose their PCD diagnosis with teachers and peers. Such concealment of symptoms and illness disclosure has been reported across chronic illness [33-36]. Results from a cystic fibrosis study [36] found that patients were more likely to disclose to romantic partners and close friends than to casual friends, bosses, or co-workers, and disclosure was associated with higher social support, social functioning, and medication adherence self-efficacy.

Poor adherence to treatments can often be a conscious decision in PCD; however, it can be the result of not making any decisions at all, e.g. worry about having PCD could lead to attempts to avoid thinking about it. Poor adherence however is likely to lead to raised anxiety about the consequences, which often leads to attempts by the individual to minimise the risks [37]. This process is known as cognitive dissonance which refers to the widespread observation that in any situation where people who feel uncomfortable about a choice they have made, also hold a strong desire to resolve this discomfort. Its resolution is central to motivating patients to change [38]. Cognitive dissonance has been reported in cystic fibrosis; however, further investigation is needed in PCD. This literature synthesis did find that symptom relief led to patients feeling 'normal' [18] but paradoxically, there was a reluctance to adhere to treatments which was also attributed to wanting to feel normal $[26,27]$. Furthermore, in a cross-sectional survey study [26], 85.7\% agreed that they had difficulty complying with treatments because they made them feel physically worse; however, $96 \%$ of patients acknowledged their health would decline without treatments. There was also a variance in the levels of PCD health literacy and in the knowledge of the preventative nature of physiotherapy among children and teenagers [18]. The perception of physiotherapy treatments, which corresponding to fluctuating levels of motivation, highlighted the need for patient centeredness and personalised medicine.

\section{Limitations}

The review has limitations. Papers included were limited to those published in the English language. It is possible that there are relevant studies published in other languages. Overall the evidence of this review is based on a small number of heterogeneous studies $(n=14)$ that are limited in size. The quality assessment of the quantitative studies revealed them to be of low quality with scores no greater than 8 points. Until recently, no disease-specific age-appropriate HRQoL measures were available for PCD patients $[17,28]$ and to date, studies have used general HRQoL tools such as the SF-36 and disease-specific tools for cystic fibrosis and COPD. These studies have also included child participants to complete measures that are not age appropriate without psychometric validation. Studies have included results where young children had help from a parent to complete these measures which may lead to bias [34]. Only one of the studies performed analyses with and without the children who needed help completing the questionnaire. In addition, limited psychometric data were presented on the validity of the HRQoL used, with some studies reporting validity but never for all of the scales. As with any review, the quality of studies included can only be assessed by what was reported in the final manuscript, e.g. missing information on any of the adopted criterion might reflect unclear reporting as opposed to a limitation in study design.

\section{Recommendations}

To date, no medications to treat PCD have been approved by regulatory bodies [30] and current physiological outcome measures such as spirometry, chest computed tomography, and lung clearance index have been reported to have limitations in terms of their sensitivity and feasibility for evaluating new therapies or disease progression [4, 39-41]. These physiological measures also do not reflect the impact of the disease on patients' daily symptoms or functioning (e.g. physical, respiratory, social) as required by the Food and Drug Administration [42] and the European Medicines Agency [43, 44]. This study has highlighted the need for large multi-national and longitudinal studies to be conducted using PCD-specific healthrelated quality of life measures (QOL-PCD) [28]. Studies are underway and QOL-PCD has been developed, validated [45] and translated comprehensively into six European languages. These tools have been included in the first international RCT azithromycin study [29]. The measures are also being included in an international PCD registry developed as part of the BESTCILIA FP7 study, providing an international platform to systematically collect data on incidence, clinical presentation, treatment, and disease course. Qualitative studies that reflect different ethnicities and cultures are important and necessary to establish the needs and opinions specific to these groups. 


\section{Conclusion}

The findings of this review indicate the physical impact, emotional and stigmatising impact of PCD. They highlight the need for well-designed, quantitative studies using PCD-specific health-related quality of life measures to accurately determine the factors that impact PCD. There is also a need for the experience of patients to be further examined across ethnicities to evaluate various nuances between cultures. This will lead to better care, management, and outcomes for PCD patients.

Funding LB, JSL and BR are participants in BEAT-PCD (COST Action 1407). LB and JSL are members of the ERS Task Force for PCD Diagnostics (ERS TF-2014-04). The National PCD Centre in Southampton is commissioned and funded by NHS England. Research in Southampton is supported by NIHR Southampton Respiratory Biomedical Research Unit, NIHR Wellcome Trust Clinical Research Facility and The AAIR Charity (Reg. No. 1129698).

\section{Compliance with ethical standards}

Conflict of interest All authors declare that they have no conflict of interest.

Ethical approval This article does not contain any studies with human participants and animals performed by any of the authors.

Open Access This article is distributed under the terms of the Creative Commons Attribution 4.0 International License (http:// creativecommons.org/licenses/by/4.0/), which permits unrestricted use, distribution, and reproduction in any medium, provided you give appropriate credit to the original author(s) and the source, provide a link to the Creative Commons license, and indicate if changes were made.

\section{References}

1. Mullowney, T., Manson, D., Kim, R., Stephens, D., Shah, V., $\&$ Dell, S. (2014). Primary ciliary dyskinesia and neonatal respiratory distress. Pediatrics, 134(6), 1160-1166.

2. Noone, P. G., Leigh, M. W., Sannuti, A., Minnix, S. L., Carson, J. L., Hazucha, M., et al. (2004). Primary ciliary dyskinesia: Diagnostic and phenotypic features. American Journal of Respiratory Critical Care \& Medicine, 169, 459-467

3. Coren, M. E., Meeks, M., Morrison, I., Buchdahl, R. M., \& Bush, A. (2002). Primary ciliary dyskinesia: Age at diagnosis and symptom history. Acta Paediatrica. 91, 667-669

4. Maglione, M., Bush, A., Montella, S., Mollica, C., Manna, A., Esposito, A., et al. (2012). Progression of lung disease in primary ciliary dyskinesia: is spirometry less accurate than CT? Pediatric Pulmonology, 47(5), 498-504.

5. Marthin, J. K., Petersen, N., Skovgaard, L. T., \& Nielsen, K. G. (2010). Lung function in patients with primary ciliary dyskinesia: a cross-sectional and 3-decade longitudinal study. American Journal of Respiratory and Critical Care Medicine, 181(11), 1262-1268.
6. Goutaki, M., Meier, A. B., Halbeisen, F. S., Lucas, J. S., Dell, S. D., Maurer, E., et al. (2016). Clinical manifestations in primary ciliary dyskinesia: Systematic review and meta-analysis. European Respiratory Journal, 48, 1081-1095.

7. Shapiro, A. J., Davis, S. D., Ferkol, T., Dell, S. D., Rosenfeld, M., Olivier, K. N., et al. (2014). Laterality defects other than situs inversus totalis in primary ciliary dyskinesia: Insights into situs ambiguus and heterotaxy. Chest, 146(5), 1176-1186.

8. Kuehni, C. E., Frischer, T., Strippoli, M. -P. F., Maurer, E., Bush, A., Nielsen, K. G., et al. (2010). Factors influencing age at diagnosis of primary ciliary dyskinesia in European children. European Respiratory Journal, 36(6), 1248-1258.

9. Strippoli, M. -P. F., Frischer, T., Barbato, A., Snijders, D., Maurer, E., Lucas, J. S. A., et al. (2012). Management of primary ciliary dyskinesia in European children: Recommendations and clinical practice. European Respiratory Journal, 39(6), 1482-1491.

10. Behan, L., Dunn Galvin, A., Masefield, S., Copeland, F., Manion, M., Rindlisbacher, B., et al. (2016). Diagnosing primary ciliary dyskinesia: an international patient perspective. European Respiratory Journal, 48, 1096-1107.

11. McManus, I. C., Mitchison, H. M., Chung, E. M. K, Stubbings, G. F., \& Martin, N. (2003). Primary ciliary dyskinesia (Siewert's/Kartagener's syndrome): Respiratory symptoms and psycho-social impact. BMC Pulmonary Medicine, 3, 4.

12. Moher, D., Liberati, A., Tetzlaff, J., Altman, D. G. (2009). Preferred reporting items for systematic reviews and meta-analyses: The PRISMA statement. PLoS Medicine, 6(7):e1000097.

13. Tsimicalis, A., Stinson, J., \& Stevens, B. (2005). Quality of life of children following bone marrow transplantation: Critical review of the research literature. European Journal of Oncology Nursing, 9(3), 218-238.

14. Savage, E., Riordan, A., \& Hughes, M. (2009). Quality of life in children with acute lymphoblastic leukaemia: A systematic review. European Journal of Oncology Nursing, 13(1), 36-48.

15. Goodwin, J., Savage, E., Horgan, A. (2016). Adolescents' and young peoples' beliefs about mental health services and care: A systematic review. Archives of Psychiatric Nursing, 30, 636-644

16. Tong, A., Sainsbury, P., \& Craig, J. (2007). Consolidated criteria for reporting qualitative research (COREQ): A 32-item checklist for interviews and focus groups. International Journal for Quality in Health Care, 19(6), 349-357.

17. Dell, S., Leigh, M., Ferkol, T., Knowles, M., Alpern, A., Behan, L., et al. (2014). Development of pediatric cross-cultural patientreported outcome measures: QOL-PCD. European Respiratory Journal, 44, 1248

18. Schofield, L. M., \& Horobin, H. E. (2014). Growing up with Primary Ciliary Dyskinesia in Bradford, UK: Exploring patients experiences as a physiotherapist. Physiotherapy Theory and Practice, 30(3), 157-164.

19. Whalley, S., \& McManus, I. C. (2006). Living with primary ciliary dyskinesia: A prospective qualitative study of knowledge sharing, symptom concealment, embarrassment, mistrust, and stigma. BMC Pulmonary Medicine, 6, 25.

20. McManus, I. C., Stubbings, G. F., \& Martin, N. (2006). Stigmatization, physical illness and mental health in primary ciliary dyskinesia. Journal of Health Psychology, 11(3), 467-482.

21. Pifferi, M., Bush, A., Di Cicco, M., Pradal, U., Ragazzo, V., Macchia, P., et al. (2010). Health-related quality of life and unmet needs in patients with primary ciliary dyskinesia. The European Respiratory Journal: Official Journal of the European Society for Clinical Respiratory Physiology, 35(4), 787-794.

22. Mirra, V., Caffarelli, C., Maglione, M., Valentino, R., Perruolo, G., Mazzarella, C., et al. (2015). Hypovitaminosis D: A novel finding in primary ciliary dyskinesia. Italian Journal of Pediatrics, 41(1), 14. 
23. Maglione, M., Montella, S., Mirra, V., Bruzzese, D., \& Santamaria, F. (2014). Long-term assessment of quality of life in primary ciliary dyskinesia: Time for new tools? Chest, 146(6), e232-e233.

24. Carotenuto, M., Esposito, M., Pasquale, F., Stefano, S., \& Santamaria, F. (2013). Psychological, cognitive and maternal stress assessment in children with primary ciliary dyskinesia. World Journal of Pediatrics, 9(4), 312-317.

25. Madsen, A., Green, K., Buchvald, F., Hanel, B., \& Nielsen, K. G. (2013). Aerobic fitness in children and young adults with primary ciliary dyskinesia. PLOS ONE, 8(8), e71409.

26. Taelman, A., Havermans, T., \& Boon, M. (2014). Adherence to treatment in children with primary ciliary dyskinesia (PCD): Identifying attitudes and perceived barriers to prescribed treatment. Pediatric Pulmonology, 49, S49-S50.

27. Taelman, A., Boon, M., Dupont, L., \& Havermans, T. (2014). Living with primary ciliary dyskinesia. European Respiratory Journal, 44, P3676.

28. Lucas, J. S., Behan, L., Dunn Galvin, A., Alpern, A., Morris, A. M., Carroll, M. P., et al. (2015). A quality-of-life measure for adults with primary ciliary dyskinesia: QOL-PCD. European Respiratory Journal, 46, 375-383.

29. Werner, C., Lablans, M., Ataian, M., Raidt, J., Wallmeier, J., Große-Onnebrink, J., et al. (2016). An international registry for primary ciliary dyskinesia. European Respiratory Journal, 47(3), 849-859.

30. Shapiro, A. J., Zariwala, M. A., Ferkol, T., Davis, S. D., Sagel, S. D., Dell, S. D., et al. (2015). Diagnosis, monitoring, and treatment of primary ciliary dyskinesia: PCD foundation consensus recommendations based on state of the art review. Pediatric Pulmonology, 51, 115-132.

31. Smith, B. A., Modi, A. C., Quittner, A. L., \& Wood, B. L. (2010). Depressive symptoms in children with cystic fibrosis and parents and its effects on adherence to airway clearance. Pediatric Pulmonology, 45(8), 756-763.

32. Modi, A. C., Driscoll, K. A., Montag-Leifling, K., \& Acton, J. D. (2011). Screening for symptoms of depression and anxiety in adolescents and young adults with cystic fibrosis. Pediatric Pulmonology, 46(2), 153-159.

33. Joachim, G., \& Acorn, S. (2000). Stigma of visible and invisible chronic conditions. Journal of Advanced Nursing, 32(1), 243-248.

34. Saunders, B. (2014). Stigma, deviance and morality in young adults' accounts of inflammatory bowel disease. Sociology of Health \& Illness, 36(7), 1020-1036.

35. Aydemir, N., Özkara Ç, Ünsal, P., \& Canbeyli, R. (2011). A comparative study of health related quality of life, psychological well-being, impact of illness and stigma in epilepsy and migraine. Seizure: The Journal of the British Epilepsy Association, 20(9), 679-685.

36. Borschuk, A. P., Everhart, R. S., Eakin, M. N., Rand-Giovannetti, D., Borrelli, B., \& Riekert, K. A. (2016). Disease disclosure in individuals with cystic fibrosis: Association with psychosocial and health outcomes. Journal of Cystic Fibrosis, 15, 696-702.

37. Duff, A. J. A., \& Latchford, G. J. (2010). Motivational interviewing for adherence problems in cystic fibrosis. Pediatric Pulmonology, 45(3), 211-220.

38. Festinger, L. (1962). A theory of cognitive dissonance. Stanford: Stanford university press.

39. Green, K., Buchvald, F. F., Marthin, J. K., Hanel, B., Gustafsson, P. M., \& Nielsen, K. G. (2012). Ventilation inhomogeneity in children with primary ciliary dyskinesia. Thorax, 67(1), 49-53.

40. Irving, S. J., Ives, A., Davies, G., Donovan, J., Edey, A. J., Gill, S. S., et al. (2013). Lung clearance index and high-resolution computed tomography scores in primary ciliary dyskinesia. American Journal of Respiratory and Critical Care Medicine, 188(5), 545-549.

41. Boon, M., Vermeulen, F. L., Gysemans, W., Proesmans, M., Jorissen, M., \& De Boeck, K. (2015). Lung structure-function correlation in patients with primary ciliary dyskinesia. Thorax, 70(4), 339-345.

42. U.S. Department of Health and Human Services; Food and Drug Administration. Guidance for Industry. Patient-Reported Outcome Measures: Use in Medical Product Development to Support Labeling Claims Dec 2009 [updated Dec 2009; cited 2015 September 24].

43. Apolone, G., De Carli, G., Brunetti, M., \& Garattini, S. (2001). Health-related quality of life (HR-QOL) and regulatory issues. An assessment of the European Agency for the Evaluation of Medicinal Products (EMEA) recommendations on the use of HR-QOL measures in drug approval. Pharmacoeconomics, 19(2), 187-195.

44. European Medicines Agency: Committee for Medicinal Products for Human Use (CMHP). Reflection paper on the regulatory guidance for the use of health related quality of life (HRQL) measures in the evaluation of medicinal products. 2005 [cited 2015 August 4].

45. Behan, L. L. M., Dell, S., Galvin, A. D., Quittner, A. L., \& Lucas, J. S. (2017). Validation of a health-related quality of life instrument for primary ciliary dyskinesia $(Q O L-P C D)$. Thorax. 